\title{
Common origin of the anterior choroidal artery and posterior communicating artery with a concomitant aneurysm at the internal carotid artery-posterior communicating artery junction: A case report
}

\author{
HAO CHEN and JINLU YU \\ Department of Neurosurgery, The First Hospital of Jilin University, Changchun, Jilin 130021, P.R. China
}

Received June 18, 2021; Accepted August 23, 2021

DOI: $10.3892 / \mathrm{mi} .2021 .12$

\begin{abstract}
The anterior choroidal artery (AChA) is one of the main arteries, and it can exhibit several anomalies, among which is the common origin of the AChA and posterior communicating artery (PcomA); however, this is relatively rare. In the case that the $\mathrm{AChA}$ originates from the PcomA, it is highly uncommon for a concomitant aneurysm to develop at the internal carotid artery (ICA)-PcomA junction. The present study reports such a case. A 58-year-old female developed a headache with nausea and vomiting. Computed tomography (CT) revealed a subarachnoid hemorrhage. CT angiography and digital subtraction angiography (DSA) revealed a right ICA-PcomA aneurysm, with the AChA arising from the proximal segment of the PcomA. The aneurysm was clipped in the hybrid operating room. DSA confirmed that the aneurysm had been clipped completely, and that the PcomA and AChA had been retained. Following surgery, the patient recovered well without any sequelae. CT angiography revealed no recurrence of the aneurysm at the 3-month follow-up. On the whole, as demonstrated by the case presented herein, when the AChA and PcomA have a common origin, the AChA and PcomA should be retained during concomitant aneurysm clipping at the ICA-PcomA to prevent severe infarction complications. Surgical clipping during hybrid surgery is a suitable choice.
\end{abstract}

Correspondence to: Dr Jinlu Yu, Department of Neurosurgery, The First Hospital of Jilin University, 1 Xinmin Avenue, Changchun, Jilin 130021, P.R. China

E-mail: jlyu@jlu.edu.cn

Abbreviations: AChA, anterior choroidal artery; CT, computed tomography; CTA, computed tomography angiography; DSA, digital subtraction angiography; PcomA, posterior communicating artery

Key words: anterior choroidal artery, posterior communicating artery, aneurysm, clipping

\section{Introduction}

The anterior choroidal artery (AChA) is one of the main arteries that needs to be retained during both craniotomy and endovascular therapy to prevent severe infarction complications (1). Generally, the AChA originates from the supraclinoid internal carotid artery (ICA), distal to the posterior communicating artery (PcomA) (2). However, the AChA can also exhibit several anomalies in its origin, development, and the course of the artery (3).

Among all possible anomalies, the common origin of the AChA and PcomA (namely the AChA originating from the PcomA) is particularly rare (4). In the study by Otomo (5), the incidence of the AChA originating from the PcomA in cadavers was only $0.4 \%$. When the AChA originates from the PcomA, a concomitant aneurysm at the ICA-PcomA junction is highly uncommon. The present study reports such a case.

The AChA and PcomA arising from a common stem is of utmost clinical significance, as once the PcomA is injured during the treatment of the PcomA aneurysm, infarction in the AChA region will inevitably occur.

\section{Case report}

A 58-year-old female was admitted to the First Hospital of Jilin University (Changchun, China) on October 29, 2019 after complaining of a headache with nausea and vomiting for $1 \mathrm{~h}$. She had a history of diabetes for 4 years and received regular insulin injections. She denied having hypertension.

Brain computed tomography (CT) displayed a subarachnoid hemorrhage (Fig. 1A). A physical examination revealed that she did not have any cognitive impairments and could flexibly move her extremities without pathological reflexes. Her Kernig sign was positive. A CT angiography revealed a right ICA-PcomA junction aneurysm (Fig. 1B and C). Digital subtraction angiography (DSA) confirmed the diagnosis of the ICA-PcomA aneurysm. The PcomA was thick, and the AChA originated from the proximal segment of the PcomA (Fig. 1D). DSA revealed that the $\mathrm{P} 1$ segment of the posterior cerebral artery (PCA) was absent, which indicated that the PCA was of the fetal type (Fig. 1E and F). Aneurysm clipping was planned in the hybrid operating room. 
A

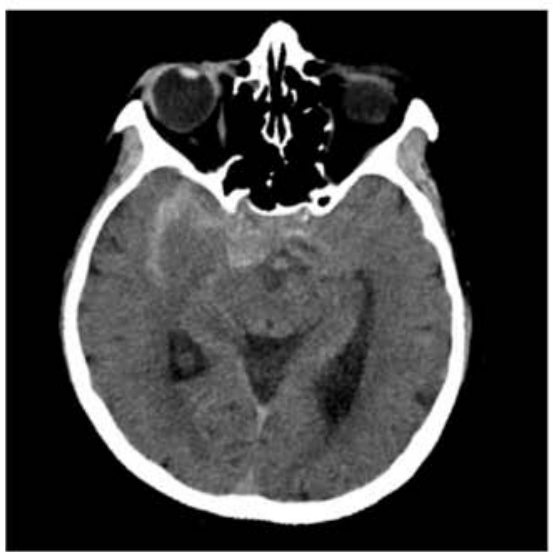

C

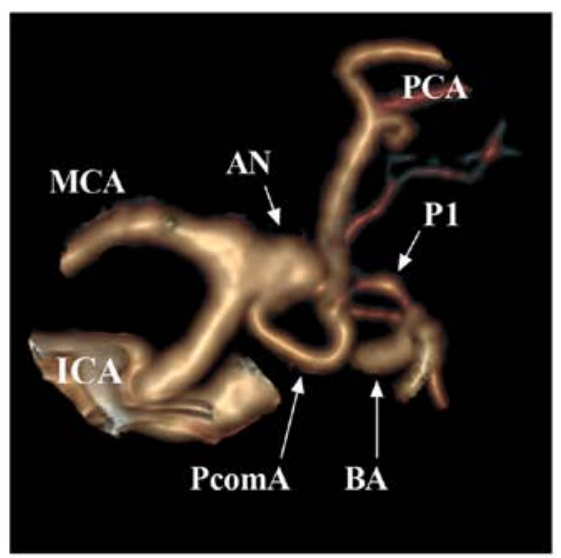

E

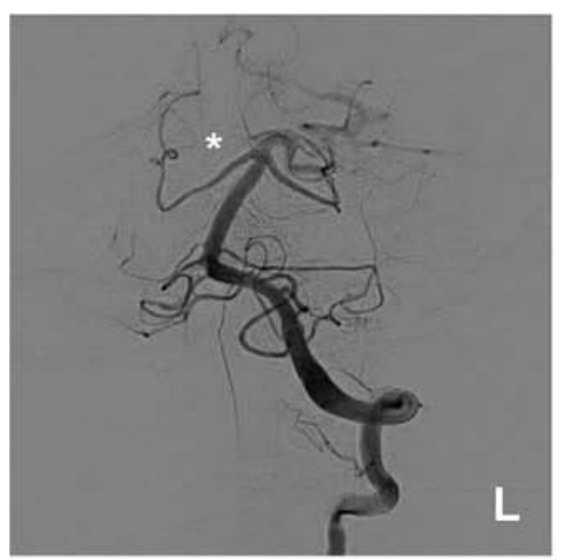

B

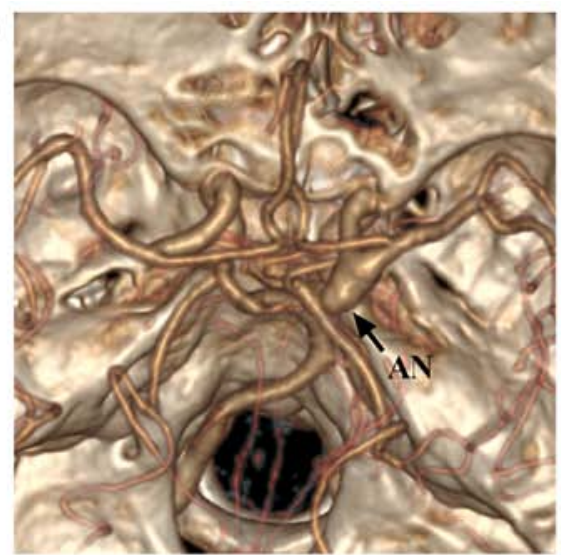

D

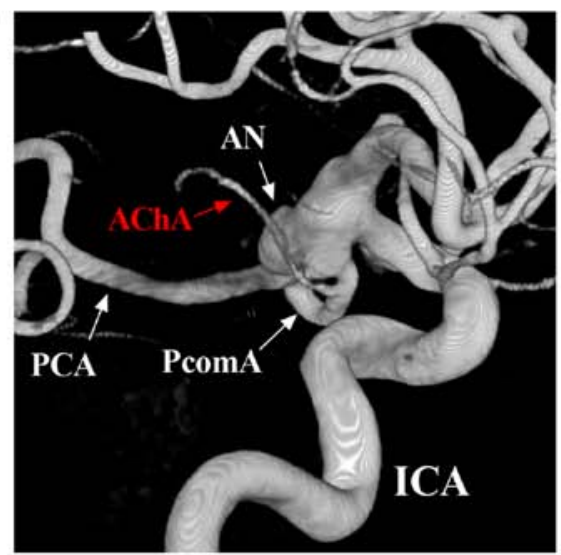

$\mathrm{F}$

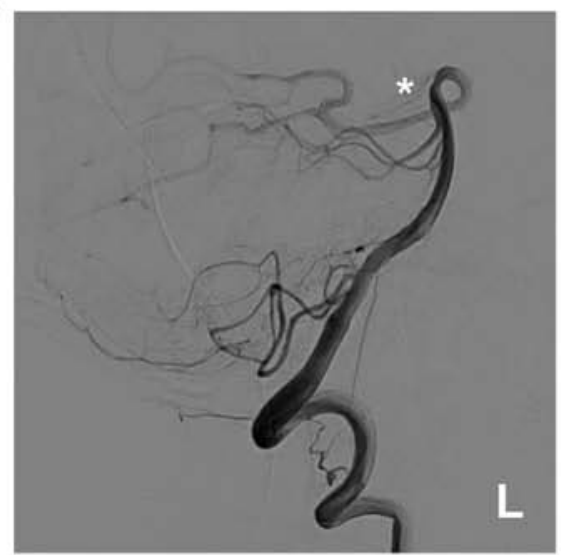

Figure 1. Preoperative images. (A) Brain CT scan illustrating the SAH in the suprasellar cistern and right lateral fissure cistern. (B) CTA illustrating the right PcomA aneurysm (arrow). (C) CTA illustrating the artery around the aneurysm. (D) 3-Dimensional DSA illustrating that the aneurysm is located at the junction of the ICA and PcomA and that the AChA arises from the proximal segment of the PcomA. (E and F) Left VA-DSA illustrating an absent right PCA (asterisks). AChA, anterior choroidal artery; AN, aneurysm; BA, basilar artery; CT, computed tomography; CTA, computed tomography angiography; DSA, digital subtraction angiography; ICA, internal carotid artery; L, left; MCA, middle cerebral artery; PCA, posterior cerebral artery; PcomA, posterior communicating artery; SAH, subarachnoid hemorrhage; P1, the first segment of PCA; VA, vertebral artery.

During craniotomy, an ICA-PcomA aneurysm was observed (Fig. 2A), and the AChA was confirmed to originate from the proximal segment of the PcomA. The aneurysm was subsequently clipped with FT853T and FT644T clips (YASARGIL ${ }^{\circledR}$ titanium clip, Aesculap AG) (Fig. 2B and C). An intraoperative DSA examination was performed immediately and confirmed that the aneurysm was clipped completely, and that the PcomA and AChA were retained (Fig. 2D and E). Following surgery, the patient recovered well without any sequelae. A CT angiography revealed no recurrence of the aneurysm at the 3-month follow-up (Fig. 2F).
Of note, informed signed consent to participate was obtained from the patient described in the study and the patient provided consent for her data to be published.

\section{Discussion}

The AChA generally originates distal to the origin of the PcomA (6). In the study by Akar et al (7), 70\% of the AChAs examined originated from the ICA and were distal to the PcomA, 20\% originated from the area immediately distal to the origin point of the PcomA, and $10 \%$ originated from the 

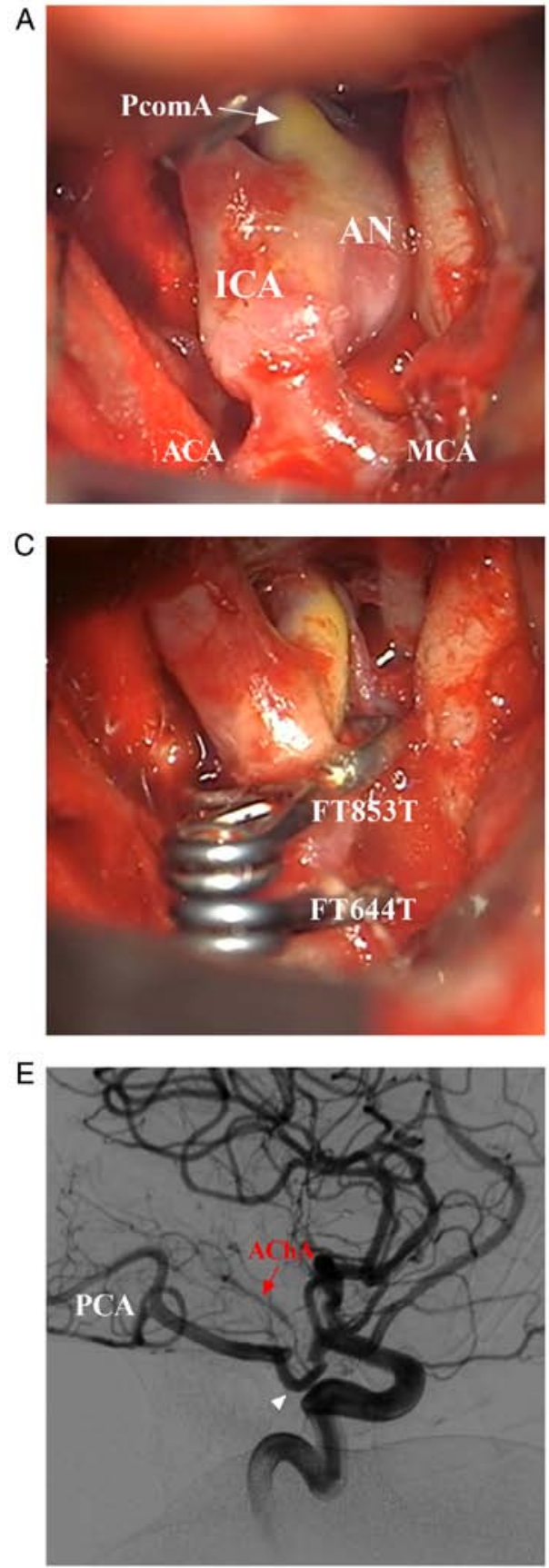

B

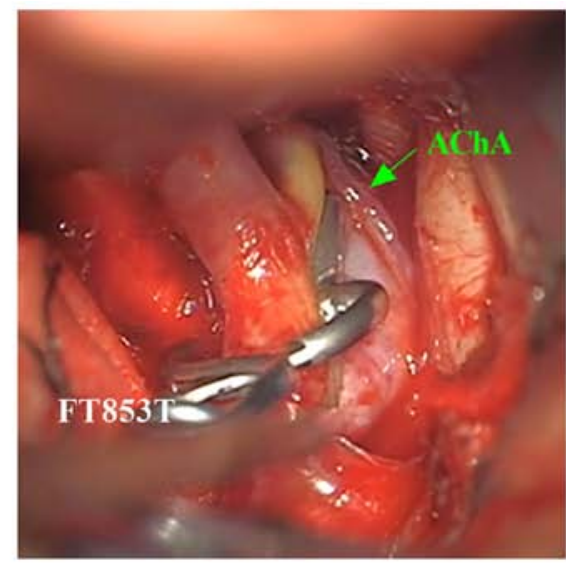

D

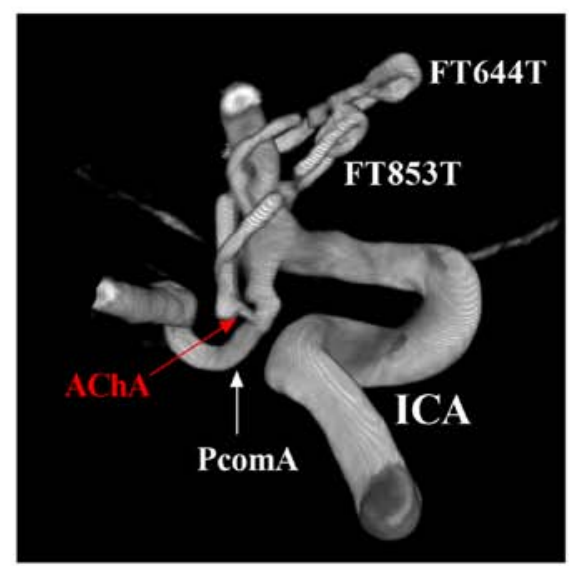

$\mathrm{F}$

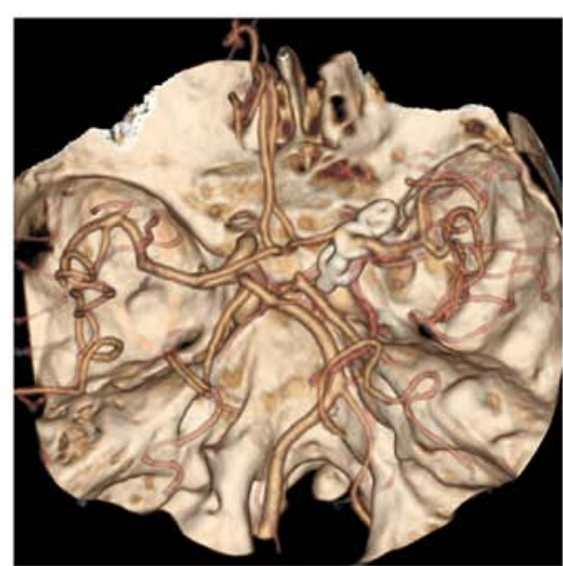

Figure 2. Intraoperative and post-operative follow-up images. (A) Intraoperative images showing the main arterial structures around the PcomA aneurysm. (B) First, the aneurysm was clipped using an FT853T clip, and the AChA (arrow) was visualized. (C) The aneurysm was clipped using an FT644T clip supplementally, and the PcomA and AChA were well retained. (D and E) Intraoperative DSA illustrating that the aneurysm was clipped completely and that the PcomA (triangle) and AChA (red arrow) were well retained. (F) CTA illustrating no recurrence of the aneurysm at the 3-month follow-up. ACA, anterior cerebral artery; AChA, anterior choroidal artery; AN, aneurysm; CTA, computed tomography angiography; DSA, digital subtraction angiography; ICA, internal carotid artery; MCA, middle cerebral artery; PCA, posterior cerebral artery; PcomA, posterior communicating artery.

area immediately proximal to the area of ICA bifurcation. Other rare origins include the area of ICA bifurcation and even the middle cerebral artery (8). In addition, the transposition of the AChA to the PcomA origin may occur (9). A duplicate branch of the AChA may also be present (10).

However, the common origin of the PcomA and AChA is the rarest among all $\mathrm{AChA}$ variants $(4,11)$. In a large cadaveric study of AChA anatomy performed by Otomo (5), 3 of the 778 anterior choroidal arteries $(0.4 \%)$ arose from the PComA. Tonetti et al (8) considered that the AChA and PcomA developed as part of the caudal division of the embryologic ICA, and thus persisted in the fully developed circulation as a shared-origin AChA and PcomA.

According to the study by Padget (12), during the embryological stage, the AChA and PcomA are independent; however, the origin of the AChA and PcomA is highly plexiform, and a number of arterial networks connect them. Subsequently, from the plexus, the two main channels develop into the AChA and PcomA. Accordingly, the PcomA and AChA embryologically share their branches and stems. This embryological background can also explain the common origin of the AChA and PcomA. 
A concomitant aneurysm at the ICA and PcomA junction is rare, and a rare case is reported herein. When an aneurysm occurs at the ICA-PcomA junction, this variation becomes extremely significant. An injured PcomA may induce catastrophic consequences as subsequent AChA ischemia can occur. During the treatment of PcomA aneurysms, PcomA injuries may not even lead to a poor prognosis if the circle of Willis is intact. This is due to the fact that following PcomA occlusion, blood can travel through the PCA from the reverse blood flow of the basilar artery.

However, in 20-30\% of the population with fetal PCA, the basilar artery is no longer the main supplying vessel to the ipsilateral PCA (13). The case reported in the present study is of a fetal PCA. In addition, DSA revealed that the AChA originated from the PcomA, which increased the difficulty of endovascular treatment as it was impossible to determine whether the reverse blood flow from the PCA would fill the AChA and to guarantee that ischemia would not occur following PcomA occlusion by endovascular treatment.

Therefore, when the aneurysm was clipped in the hybrid operation, the AChA originating from the PcomA was clearly visualized during clipping, the aneurysm was confirmed to have been clipped completely, and the AChA of the PcomA was retained.

In conclusion, the AChA and PcomA may have a common origin in rare cases, and this anomaly may even be combined with aneurysm at the ICA-PcomA junction, which should be detected and addressed with caution, particularly in cases of fetal PcomA, and the PcomA should be retained to prevent AChA infarction. Surgical clipping in hybrid operations is controllable and thus a suitable choice.

\section{Acknowledgements}

Not applicable.

\section{Funding}

No funding was received.

\section{Availability of data and materials}

The datasets used and/or analyzed during the current study are available from the corresponding author upon reasonable request.

\section{Authors' contributions}

HC and JY designed the study and drafted the manuscript. HC collected the data. JY and HC confirm the authenticity of all the raw data. All authors have read and approved the final manuscript.

\section{Ethics approval and consent to participate}

Ethics approval was not required by our institution as the present study is a case report. Informed signed consent to participate was obtained from the patient.

\section{Patient consent for publication}

The patient provided consent and agreed for her data to be published.

\section{Competing interests}

The authors declare that they have no competing interests.

\section{References}

1. $\mathrm{Yu} \mathrm{J}, \mathrm{Xu} \mathrm{N}, \mathrm{Zhao} \mathrm{Y}$ and $\mathrm{Yu} \mathrm{J}$ : Clinical importance of the anterior choroidal artery: A review of the literature. Int J Med Sci 15: 368-375, 2018.

2. Iihoshi S, Nonaka T, Miyata K and Houkin K: Angiographic analysis of variations and anomalous origin of the anterior choroidal artery and posterior communicating artery. No Shinkei Geka 38: 523-530, 2010 (In Japanese).

3. Doi K, Mizuno T, Shigematsu Y, Kobayashi O, Takezaki T, Muta D and Nishi T: A new type of hyperplastic anterior choroidal artery. J Clin Neurosci 51: 72-74, 2018.

4. Mamaliga T, White AC, Khattar NK and Hadi M: Anomalous origin of the anterior choroidal artery proximal to an ipsilateral fetal posterior cerebral artery: Case report of an extremely rare anatomic variant and discussion of its clinical implications. Cureus 11: e6442, 2019.

5. Otomo E: The anterior choroidal artery. Arch Neurol 13: 656-658, 1965 .

6. Takahashi S, Suga T, Kawata Y and Sakamoto K: Anterior choroidal artery: Angiographic analysis of variations and anomalies. AJNR Am J Neuroradiol 11: 719-729, 1990.

7. Akar A, Sengul G and Aydin IH: The variations of the anterior choroidal artery: An intraoperative study. Turk Neurosurg 19: 349-352, 2009.

8. Tonetti DA, Andrews EG, Stabingas K, Tyler-Kabara E, Gross BA and Jadhav A: Posterior communicating artery giving rise to shared-origin anterior choroidal artery: Case illustration. World Neurosurg 109: 413-415, 2018.

9. Choi CY and Lee CH: Transposition of anterior choroidal artery and posterior communicating artery origin. J Korean Neurosurg Soc 52: 240-242, 2012.

10. Chenin L, Chivot C, Toussaint P, Deramond H and Peltier J: An unusual, duplicate origin of the anterior choroidal artery with aneurysm: A case report. Surg Radiol Anat 37: 1273-1275, 2015.

11. Uchino A, Kamide T and Kurita H: Replaced posterior cerebral artery (PCA): Origin of all branches of the PCA from the anterior choroidal artery diagnosed by MR angiography. Surg Radiol Anat 41: 703-705, 2019.

12. Padget DH: The development of the cranial arteries in the human embryo. Contrib Embryol 32: 205-229, 1948.

13. Zampakis P, Panagiotopoulos V, Petsas T and Kalogeropoulou C: Common and uncommon intracranial arterial anatomic variations in multi-detector computed tomography angiography (MDCTA). What radiologists should be aware of. Insights Imaging 6: 33-42, 2015.

This work is licensed under a Creative Commons Attribution-NonCommercial-NoDerivatives 4.0 International (CC BY-NC-ND 4.0) License. 